\title{
Endoscopic Treatment of a Total Ileorectal Anastomosis Stenosis using Magnets
}

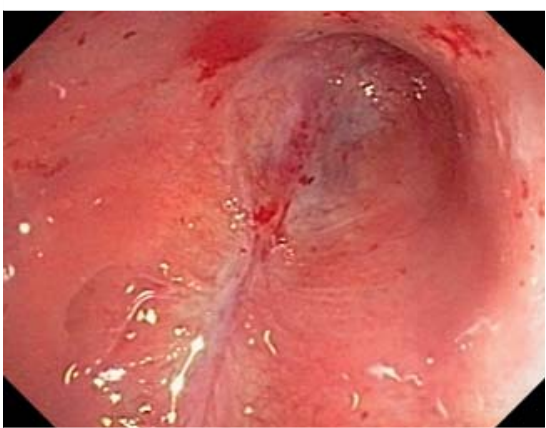

- Fig. 1 Endoscopic view of complete anastomosis stenosis.

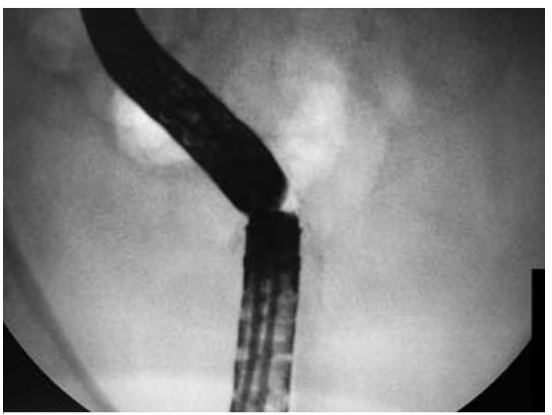

Fig. 2 A simultaneous endoscopic examination of the rectal stump and the distal ileum, under radioscopic vision, demonstrating a space smaller than $1 \mathrm{~cm}$.
The use of magnets in endoscopy has been described for more than 20 years [1]. Magnetic compression anastomosis has been described in experimental animal models as well in clinical use [2]. Chopita and colleagues demonstrated the results of magnetic endoscopic gastroenteric anastomosis in humans with a success rate of $86.6 \%$ [3]. Other authors have used magnets to treat refractory strictures of the esophagus and total stenosis of the biliary tract [4]. Trials with compression anastomosis involving the rectum have already been reported in swine models. A few cases have also been described [5].

We report a case of a 57-year-old man with familial adenomatous polyposis and three focuses of colonic adenocarcinoma who underwent total colectomy with ileorectal anastomosis reconstruction 2 years ago. In the postoperative period, a protective ileostomy was performed owing to the occurrence of anastomosis dehiscence. A few days later, laparotomy was performed with closure of the rectal and ileal stumps and preserving the ileostomy. After 18 months, reconstruc- tion of the intestinal tract was performed, with latero-terminal ileorectal anastomosis, using a 25-mm endoluminal stapler. The procedure was completed with difficulty considering the intense pelvic fibrosis that had developed from the previous procedures that were selected for ileostomy maintenance. Three months later, during control retroscopy to schedule ileostomy closure, complete anastomosis stenosis was observed (ฉ Fig. 1). A simultaneous endoscopic examination of the rectal stump and the distal ileum was done, under radioscopic vision, demonstrating a space smaller than $1 \mathrm{~cm}$ between the two segments ( Fig.2). Endoscopic treatment with magnetic compression anastomosis was proposed ( $>$ Fig. $3, \triangleright$ Fig. 4 ) and successfully completed ( $\triangleright$ Video 1 ), with the creation of a new and wide ileorectal anastomosis ( $\mathbf{F i g . 5}$ ) that allowed the ileostomy closure 8 days later. A control endoscopic exam done 15 days, 1 month, and 2 years later demonstrated patent anastomosis.

Endoscopy_UCTN_Code_TTT_1AQ_2AF

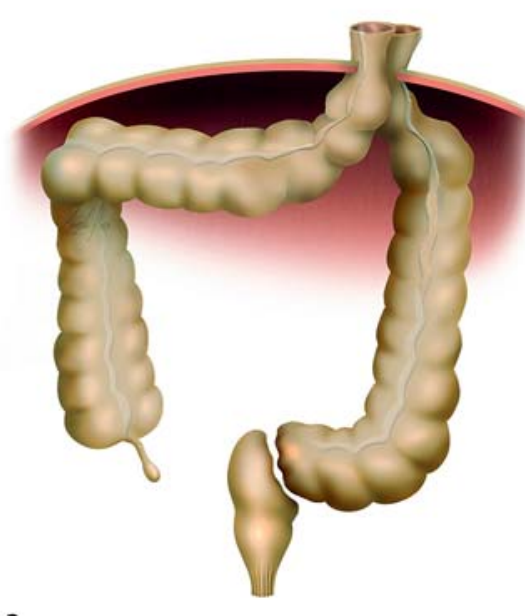

a

b

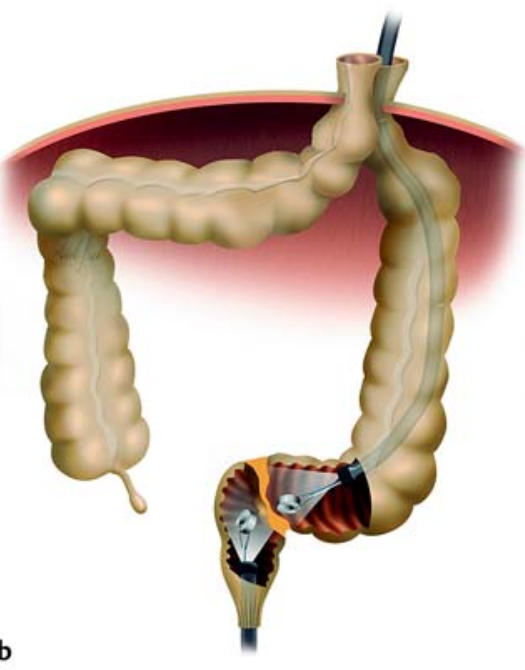

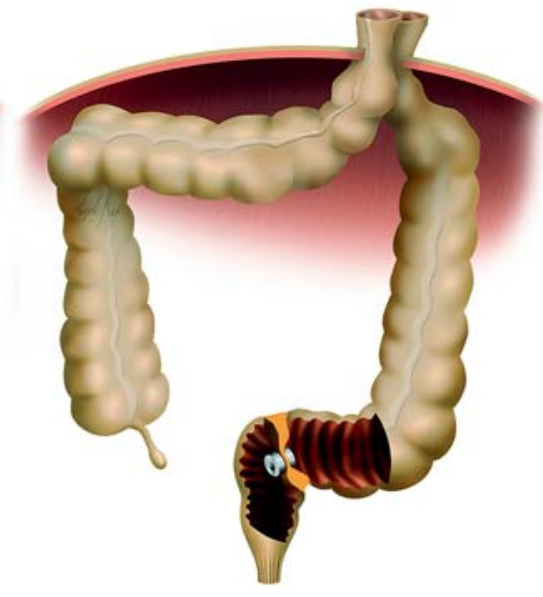

c

Fig. 3 Illustration showing: a completely stenosed rectal anastomosis; $\mathbf{b}$ endoscopic introduction of the magnets in ideal and rectal side; c the magnets in place. Source: Angela Giseli de Souza. 


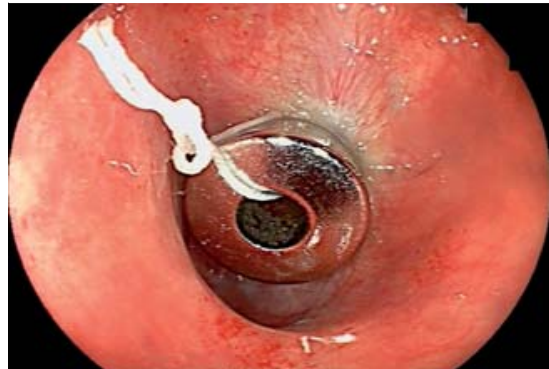

Fig. 4 The magnet in a rectal stump.

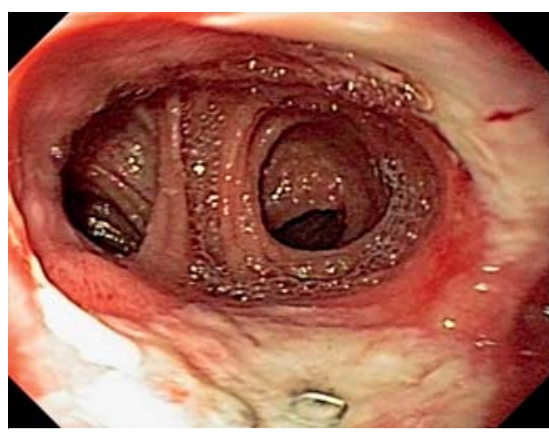

Fig. 5 The final appearance of the new lumen of the anastomosis.

\section{Competing interests}

The authors declare that they have no conflict of interest.

The authors

Guilherme Francisco Gomes ${ }^{1}$, Rafael William Noda ${ }^{1}$, Thienes Maria da Costa Lima ${ }^{1}$, Eduardo Carboni da Silva', Leandro Yoshimi Kashiwagui ${ }^{1}$, Thaisa Sami Nakadomari ${ }^{1}$, Marciano Anghinoni ${ }^{2}$

1 Endoscopy Unit, Hospital Nossa Senhora das Graças, Curitiba, Brazil

2 Oncologic Surgery Unit, Hospital Nossa Senhora das Graças, Curitiba, Brazil

\section{Corresponding author}

\section{Guilherme F. Gomes, MD}

Rua Luis Tramontin, 1345, CEP 81230161 ,

Curitiba, Parana, Brazil

guilfgomes@gmail.com

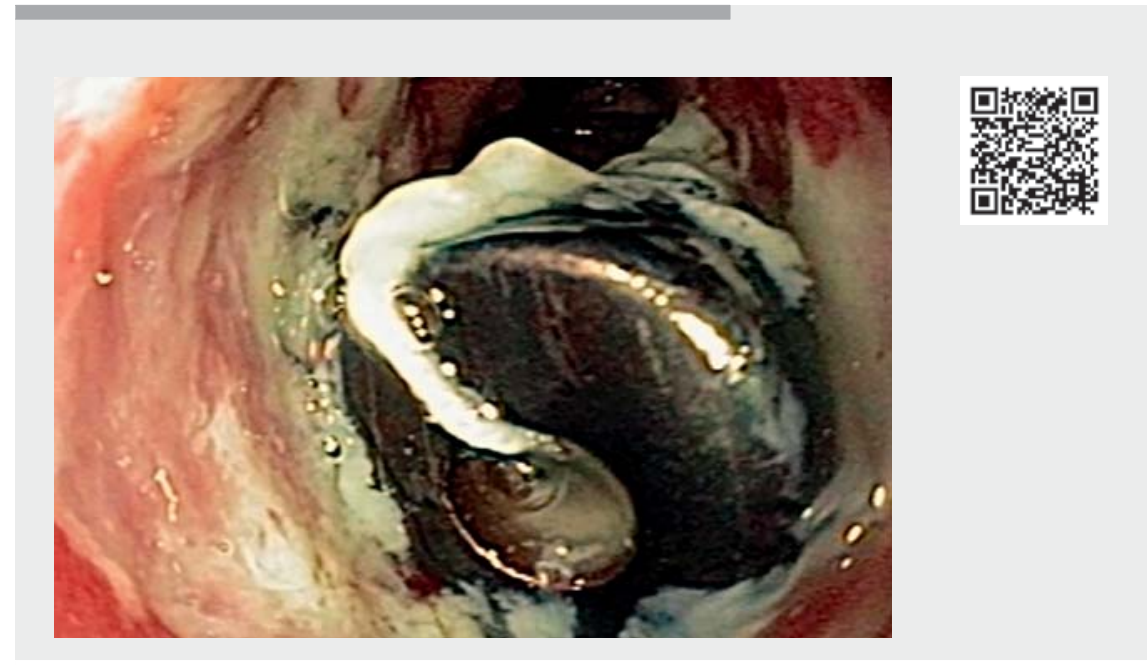

$\checkmark$ Video 1 Endoscopic treatment of a total ileorectal anastomosis stenosis using magnets. Source for graphical illustration: Angela Giseli de Souza.

References

[1] Equen M, Roach G, Brown R et al. Magnetic removal of foreign bodies from the esophagus, stomach and duodenum. AMA Arch Otolayngol 1957; 66: 698-706

[2] Bruns NE, Gleen IC, Craner DR et al. Magnetic compression anastomosis (magnamosis) in a porcine esophagus: proof of concept for potential application in esophageal atresia. J Pediatr Surg 2019; 54: 429-433

[3] Chopita N, Vaillaverde A, Cope C et al. Endoscopic gastroenteric anastomosis using magnets. Endoscopy 2005; 37: 313-317

[4] Jang SI, Lee K-H, Yoon HJ et al. Treatment of completely obstructed benign biliary strictures with magnetic compression anastomosis: follow-up results after recanalization. Gastrointest Endoscopy 2017; 85: 10571066

[5] Zaritzky M, Ben MR, Johnston K. Magnetic gastrointestinal anastomosis in pediatric patients. J Pediatr Surg 2014; 49: 11311137

\section{Bibliography}

Endoscopy 2022; 54: E300-E301

DOI 10.1055/a-1524-0868

ISSN 0013-726X

published online 2.7.2021

(c) 2021. Thieme. All rights reserved.

Georg Thieme Verlag KG, Rüdigerstraße 14,

70469 Stuttgart, Germany

\section{ENDOSCOPY E-VIDEOS}

https://eref.thieme.de/e-videos

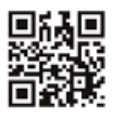

Endoscopy E-Videos is an open access online section, reporting on interesting cases and new techniques in gastroenterological endoscopy. All papers include a high quality video and all contributions are freely accessible online. Processing charges apply (currently EUR 375), discounts and wavers acc. to HINARI are available.

This section has its own submission website at

https://mc.manuscriptcentral.com/e-videos 